\title{
SARAWAK COVID-19: EFFECTS OF PRE-FESTIVAL MOBILITY AND FESTIVAL GATHERINGS
}

\author{
Jane Labadin* \\ Universiti Malaysia Sarawak, Malaysia \\ Boon-Hao Hong \\ Universiti Malaysia Sarawak, Malaysia \\ Poline Bala \\ Universiti Malaysia Sarawak, Malaysia \\ Juna Liau \\ Universiti Malaysia Sarawak, Malaysia \\ Helmy Hazmi \\ Universiti Malaysia Sarawak, Malaysia
}

\begin{abstract}
Gathering to celebrate festivals is a common socio-cultural practice amongst Sarawak's diverse groups. For untold years, individuals, households, villages and at times the entire communities get together to observe their various religious, cultural and community festivals. However, during the COVID-19 pandemic period, the practice of gathering to celebrate those festivals became a challenging practice. This is because density of population and intensity of social contacts are deemed to increase SARS-CoV-2 high transmissibility. In this paper, we analyzed the trend of COVID-19 active cases in Sarawak in the first half of the year 2021 and calibrated the parameter signifying the proportion of exposed population taking effective precautionary measures, $\kappa$ in our model. Our findings suggest that after every festival celebration the value of $\kappa$ is decreased, leading to the increased number of active cases. In addition, the pre-festival mobility change involving visits to the retail and grocery stores are higher than any other time. Therefore, the festival gatherings and increased pre-festival mobility are catalysts that accelerated the increment of the number of active COVID-19 cases in Sarawak. In light of this, we proposed that any form of festival related gathering ought to be avoided in order to curb any forms of outbreak in Sarawak.
\end{abstract}

Keywords: Covid-19, Mathematical Modeling, Festival, Gathering, Seir.

* Corresponding author: Faculty of Computer Science and Information Technology, Universiti Malaysia Sarawak, Kota Samarahan 94300 Malaysia; Email: ljane@unimas.my 


\section{INTRODUCTION}

Mass gathering has been identified as one of the accelerating factors for COVID-19 outbreak (Brandl et al., 2020; McCloskey et al., 2020). For instance, in Malaysia, there are two significant mass gathering events which have led to the second and third waves of the outbreak in the nation. The first was the Tabligh gathering event (Che Mat et al., 2020; Dass et al., 2021) and the other was the Sabah election (Lim et al., 2021), which was held on the 26 September 2020. Unlike Peninsular Malaysia and Sabah, the region of Sarawak was spared from the third wave of the outbreak. This is mainly because the Sarawak government, through its State Disaster Management Committee (SDMC), has taken a quick response to prevent transmission by banning all travels from Sabah (CodeBlue, 2020). Hence, Sarawak reported a total of only 10 active cases on the 16 December 2020. This number is significant in the context of a massive wave, which has hit the nation as a whole with a staggering 11,867 total active cases on the same day. In fact, the first quarter of the year 2021 saw a gradual increase of daily active cases of COVID-19 in Sarawak, and there was a delay in the increment of cases when contrasted with the rise seen in Malaysia as a whole. Judging from the daily active COVID-19 cases since January 2021, it is apparent that Sarawak has yet to reach the peak.

Unlike with Peninsular Malaysia and Sabah, the third wave of COVID-19 outbreak in Sarawak is due to a funeral family gathering in a longhouse area which has led to a total of 12 clusters, 3725 cases, and 31 death (Tawie, 2021). The incident suggests that even though communities are aware of higher risk of infection associated with mass gathering, they still ignored the Standard Operating Procedures (SOP) in part because they perceived "...funerals are public events: they are a communal responsibility" (Metcalf, 1982: 150). Hence despite the SOP such as wearing of masks and physical distancing were already put in place, these were neglected in communal settings and thus risking higher transmission. As discussed in Boccia (2021), family gatherings at festival times during a pandemic should be avoided to prevent household outbreaks. This is simply because during such gathering, a family member from a different area might be infected with COVID-19 but remain asymptomatic, while quietly harbouring the virus to those in attendance. During the third wave of the outbreak, Malaysians celebrated three different festivals, namely Christmas, Chinese New Year, and Hari Raya Aidilfitri. The SOP regarding celebration of these festivals were enforced by limiting the number of social visits among celebrants during the first day of the celebrations. Although the number of visitors were limited, still there were several transmission clusters which are closely linked to social visits carried out during those festival (Geraldine, 2021; Ling, 2021a; The Star, 2021a).

In this paper, in order to explore the nature of social gathering-based transmission we present a simulation to illustrate the compliance of the SOP during the pre-festival and festival periods in Sarawak, particularly during the Harvest Festival celebration known as Hari Gawai. Most existing research articles, aforementioned focused on mass gathering events in Malaysia, however those were not the primary factor leading to the third wave of outbreak in Sarawak. We explored several scenarios on the effects of social gathering during the Hari Gawai; it was found that any forms of gathering such as funeral services, family gatherings or community-based social gathering has great potentials to increase the number of cases in Sarawak. 


\section{METHOD}

We collected and observed Sarawak daily active cases for COVID-19 from 1 January to 6 June 2021 from Sarawak Disaster Management Committee (SDMC) official Facebook page which can be accessed at https://www.facebook.com/SarawakDisasterInfo/. We then use our in-house simulation tool namely COVID-MYSim which can be found at https://fcsit.shinyapps.io/COVID-19_mal/ to calibrate the degree of SOP compliance in Sarawak. This tool is developed based on a deterministic Susceptible-Traced-ExposedQuarantined-Isolated-Recovered (STEQIR) model (Gill et al., 2020). The STEQIR model has two significant parameters that define the contact rates that occurred in the model. The parameter $\zeta$ that represents the effect of physical distancing of which the value is assumed to follow the official movement restrictions imposed and the parameter $\kappa$ which corresponds to the proportion of the exposed individuals complying to the practice of hand-hygiene, use of face masks, and any other forms of precautionary measures such as avoiding crowded places and so on. The higher the value of $\kappa$ indicates that every individual in the population complies with the current SOP.

\section{RESULT AND DISCUSSION}

Through our simulations using COVID-MySim tool, we explored the cause of the rise in the COVID-19 cases in Sarawak by suggesting the possibility of physical gatherings occurred. The major gatherings that could and thus may affect the spread of the disease are the celebrations of Chinese New Year (12 - 13 February 2021), Hari Raya Aidilfitri (13 - 14 May 2021) and Gawai festivities (1 - 2 Jun 2021). Apart from that, gathering or crowding may occur during the period of when school reopened in the first quarter of the year.

Figure 1: Sarawak daily total active COVID-19 cases (from 1 January to 21 May) with the simulations provided by COVID-MySim with $95 \%$ confidence interval. Calibration of the parameters are shown in Table 1 


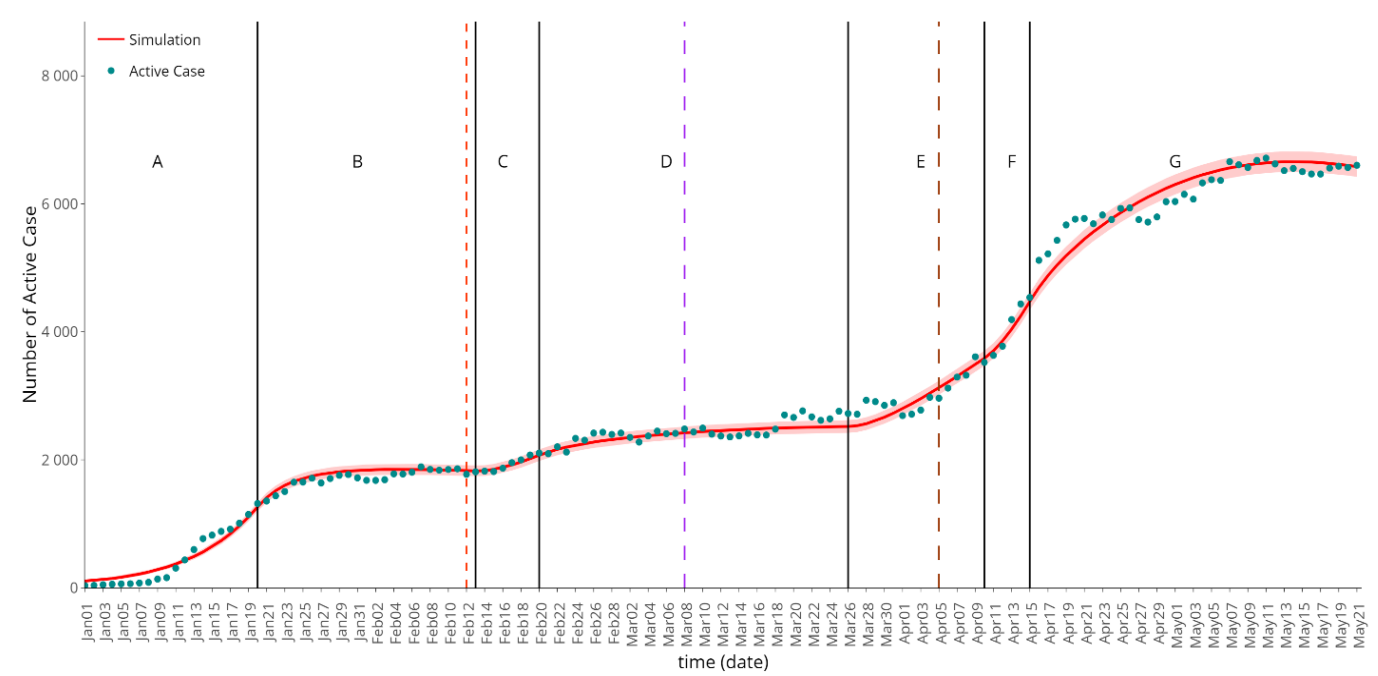

Table 1: Calibration of the parameters value and $R_{t}$ for each segment labelled in Figure 1 .

\begin{tabular}{ccccc}
\hline \hline Segment & Period & Kappa & Zeta & $\mathbf{R}_{\mathbf{t}}$ \\
\hline $\mathbf{A}$ & 1 Jan - 20 Jan 2021 & 0.10 & 24 & 2.78 \\
$\mathbf{B}$ & 21 Jan - 13 Feb 2021 & 0.63 & 23 & 1.10 \\
$\mathbf{C}$ & 14 Feb - 20 Feb 2021 & 0.49 & 23 & 1.51 \\
$\mathbf{D}$ & 21 Feb - 26 Mar 2021 & 0.60 & 24 & 1.24 \\
$\mathbf{E}$ & 27 Mar - 10 Apr 2021 & 0.47 & 24 & 1.64 \\
$\mathbf{F}$ & 11 Apr - 15 Apr 2021 & 0.27 & 23 & 2.16 \\
$\mathbf{G}$ & 16 Apr - 21 May 2021 & 0.45 & 23 & 1.63 \\
\hline \hline
\end{tabular}

Figure 1 depicts the current situation in Sarawak from 1 January to 22 May where the green dots indicate the daily total active cases defined as positive COVID-19 cases which are yet to recover and are still in hospitals or quarantine centres. To calibrate the trend of outbreak in Sarawak, we divided the period into several segments, labelled in Figure 1 and listed in Table 1. We have noticed that there were two sudden surges in the number of active cases, specifically in the 20 January to 26 March 2021 range, and the 8 March to 5 April 2021 range. The first surge could presumably be due to the Christmas and New Year celebrations (25 December 2020 and 1 January 2021 respectively), while the second surge could be due to the Chinese New Year celebration (12 February 2021) and the reopening of schools (8 March and 5 April 2021). For convenience purposes, we have indicated the events in Figure 1 shown as the coloured dashed lines. Then, the schools were closed starting from 20 April 2021 and have remained closed as of 16 June 2021.

When we simulated the daily total active cases and calibrated the two parameters mentioned earlier, we noticed that the parameter $\kappa$ had to be reduced (from 0.60 to 0.27 ) indicating a complacency within the pandemic situation and the possibility of becoming less vigilant resulting in the failure to comply with the existing SOP. However, it appears that there was yet another 
sudden surge from the 23 May 2021 onward as illustrated in Figure 2, which could be due to the Hari Raya celebration.

Figure 2: Sarawak daily total active COVID-19 cases (from 4 April to 6 June) with the simulations provided by COVID-MySim with $95 \%$ confidence interval.

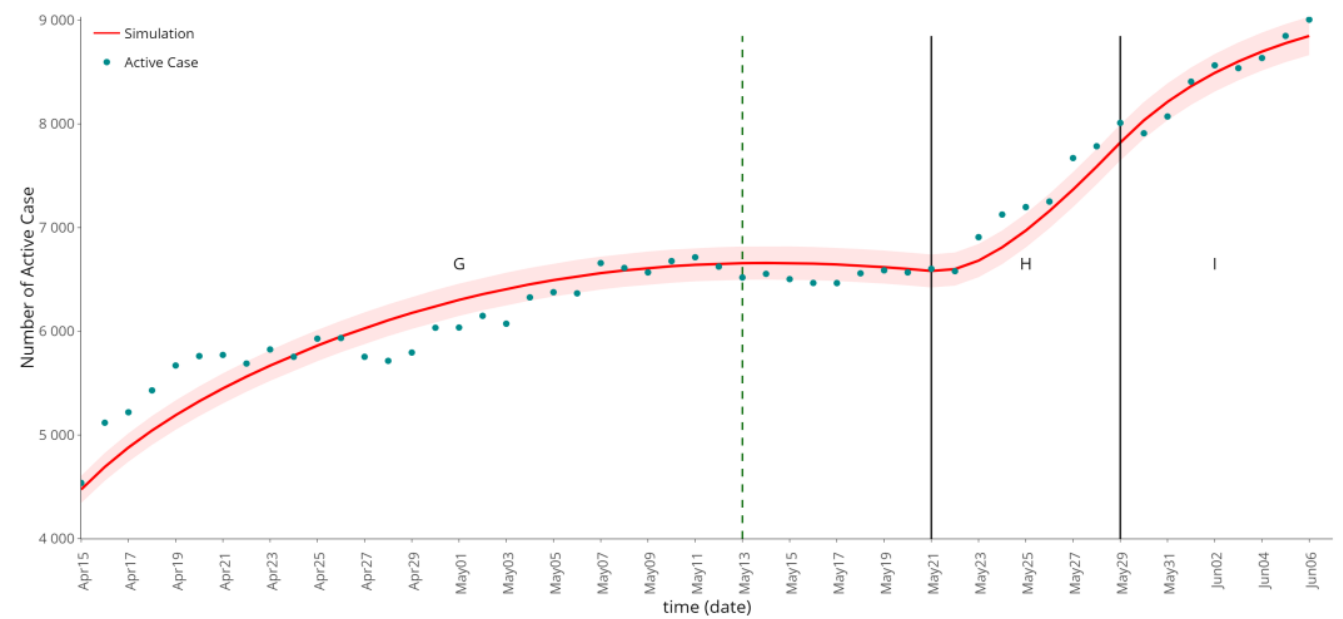

Figure 2 depicts the simulations with the introduction of another breakpoint as listed in Table 2 capturing the effects of Raya celebration. With the new breakpoint, the value of $\kappa$ was further reduced to 0.2 indicating a mere $20 \%$ of the exposed population that comply to the SOP and the rest did not. The SOP in-placed includes the no visitation during the celebration. In order to curb the rising number of the daily total active cases this value of $\kappa$ need to increase to at least 0.35 or more, which means the need of more than $35 \%$ of the population to adhere to the SOP. Sarawak maintained the Conditional Movement Control Order (CMCO) from 7 May to 17 May instead of following the MCO implemented in Peninsular Malaysia where the SOP for CMCO is tighten further by prohibiting dine-in (Ling, 2021b). However, it only made the value of $\kappa$ increase to 0.3 , which is lower than the suggested value 0.35 .

Table 2: Calibration of the parameters value for each extended segment $\mathrm{H}$ and I in Figure 2.

\begin{tabular}{ccccc}
\hline \hline Segment & Period & Kappa & Zeta & $\mathbf{R}_{\mathbf{t}}$ \\
\hline $\mathbf{H}$ & 22 May - 29 May 2021 & 0.20 & 23 & 2.37 \\
$\mathbf{I}$ & 30 May - 06 June 2021 & 0.30 & 22 & 1.98 \\
\hline \hline
\end{tabular}

Additionally, the festival effects we have highlighted above include the pre-festival activities as well. Prior to the festivals, most people will visit the retail and grocery stores to buy festival related supplies; a practice that has caused public places to be more crowded than usual. In order to assess the situation, we have used the Google mobility 
data collected from https://www.google.com/COVID19/mobility/ to show that the mobility prior to the festival dates is higher than usual which is shown in Figure 3.

Figure 3: Google mobility data from 1 December 2020 to 30 May 2021 in Sarawak whereas Category 1 is the mobility percentage change of retail and recreation while Category 2 is the mobility percentage change of grocery and pharmacy.

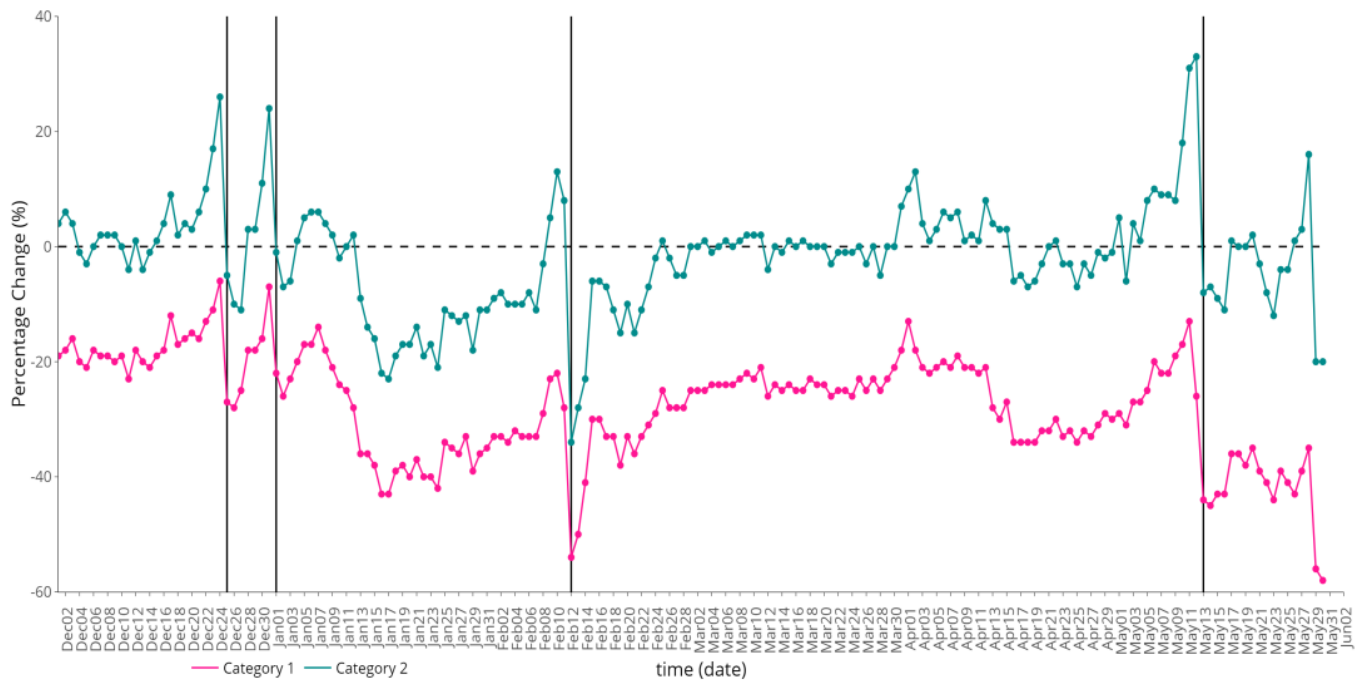

Figure 3 depicts the google mobility data according to two categories: category 1 refers to retail and recreation and category 2 includes grocery and pharmacy visits. The two categories have illustrated the mobility change of the population in Sarawak from 1 December to 30 May 2021. To demonstrate the significance of the pre-festival, we have annotated the vertical black solid lines to indicate festival celebrations such as Christmas, New Year, Chinese New Year and Hari Raya Aidilfitri. We noticed that before each festival, the mobility of both categories is higher than usual, henceforth suggesting that this is one of the factors that led to the decrease of the value of $\kappa$ after a festival season.

Based on the observations discussed above, any forms of social gatherings have affected the daily total active cases of COVID-19 in Sarawak, and these effects were seen between one to four weeks after the events. Should the situation continue, especially during the 2021 Gawai festivities celebration, Figure 4 depicts the scenario where the effects come in two weeks later.

Figure 4: Simulations of daily total active cases in Sarawak with varying values of $\kappa$, two weeks after Gawai festivities celebration. 


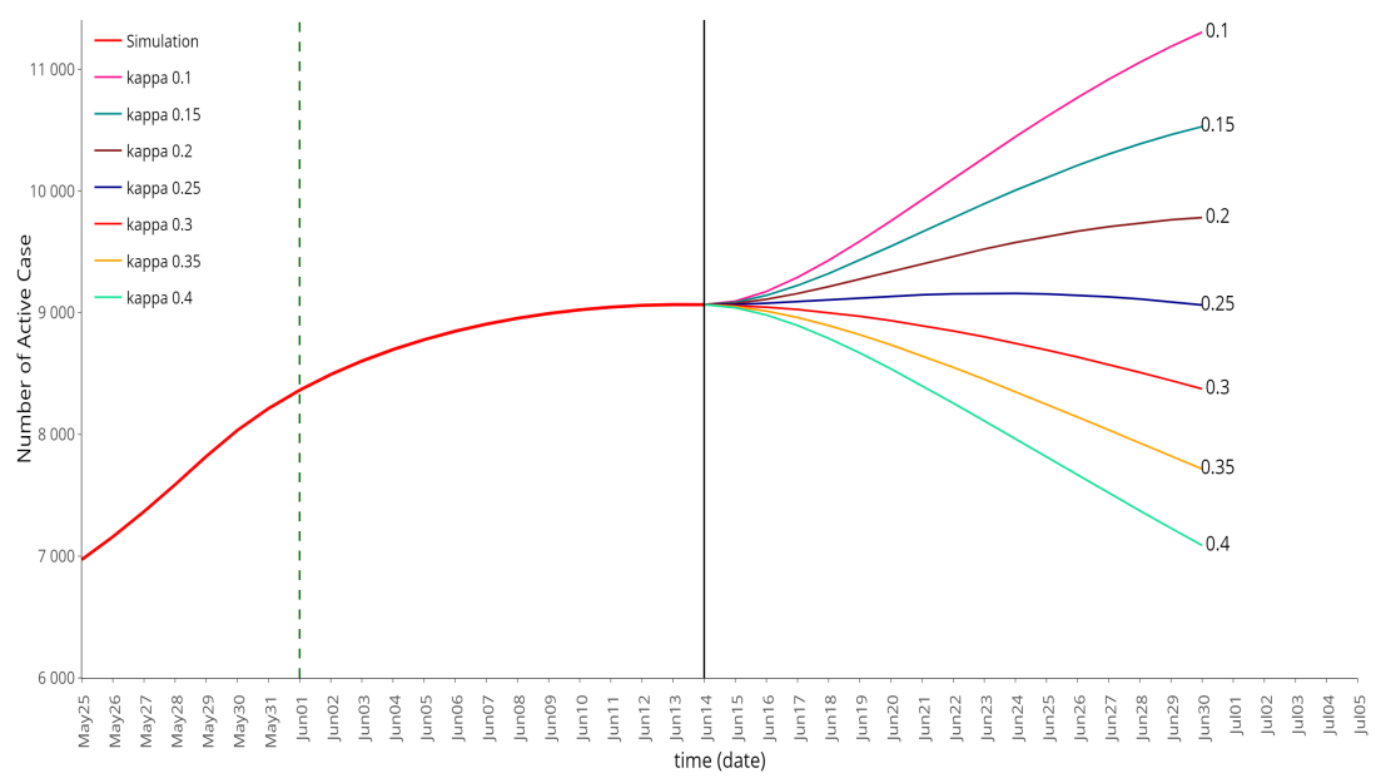

In Figure 4, we noticed that if the $\kappa$ is slightly decreased then it will lead to an increment in the number of active cases. Therefore, in order to halt the increase of the number of cases, everyone in the population needs to comply with the SOP namely avoiding 3C (Crowded places, Confined spaces, Close conversations) and doing the 3W (Wash, Wear masks, Warn). Due to the implementation of the current SOP, physical distancing and wearing masks are compulsory in a public place, thus the mobility of the people is the key factor to affect the value of $\kappa$. The MCO had been implemented on 29 May 2021 thus we expect the mobility of category 1 and category 2 will further decrease. Thus, during the Gawai festivities celebration 2021 in Sarawak, it was recommended that the population must adhere to the SOP especially by refraining from social visitations during the celebration.

\section{CONCLUSION}

This study aimed to examine the effects of social gathering especially during festival seasons in Sarawak. The value of $\kappa$ is found to be decreased after every festival in the simulation which suggest that the compliance to the SOPs during festivals is lower compared to the other nonfestival period. This study also depicts the effects of pre-festival mobility as another key factor leading to the early increment of cases post-festival. Therefore, in order to curb the outbreak in Sarawak, any form of gatherings is strongly discouraged, and that the population are urged to highly comply with the SOP during the COVID-19 pandemic. 


\section{REFERENCES}

Boccia, S. (2021). Christmas Festivities and COVID-19: A Foreseeable Risk to Anticipate. Frontiers in Public Health, 8, 639647-639647. https://doi.org/10.3389/fpubh.2020.639647

Brandl, M., Selb, R., Seidl-Pillmeier, S., Marosevic, D., Buchholz, U., \& Rehmet, S. (2020). Mass gathering events and undetected transmission of SARS-CoV-2 in vulnerable populations leading to an outbreak with high case fatality ratio in the district of Tirschenreuth, Germany. Epidemiology and Infection, 148, e252. https://doi.org/10.1017/S0950268820002460

Che Mat, N. F., Edinur, H. A., Abdul Razab, M. K. A., \& Safuan, S. (2020). A single mass gathering resulted in massive transmission of COVID-19 infections in Malaysia with further international spread. Journal of Travel Medicine, 27(3). https://doi.org/10.1093/jtm/taaa059

CodeBlue. (2020). Sarawak Enforces 14-Day Quarantine For Peninsula Travellers, Bars NonSarawakians From Sabah, Labuan. https://codeblue.galencentre.org/2020/10/01/ sarawak-enforces-14-day-quarantine-for-peninsula-travellers-bars-non-sarawakiansfrom-sabah-labuan/

Dass, S. C., Kwok, W. M., Gibson, G. J., Gill, B. S., Sundram, B. M., \& Singh, S. (2021). A data driven change-point epidemic model for assessing the impact of large gathering and subsequent movement control order on COVID-19 spread in Malaysia. PloS one, 16(5), e0252136. https://doi.org/10.1371/journal.pone.0252136

Geraldine, A. (2021). Sabah CNY family dinner creates new Covid-19 cluster. New Straits Times. https://www.nst.com.my/news/nation/2021/02/668374/sabah-cny-family-dinner-createsnew-covid-19-cluster

Gill, B. S., Jayaraj, V. J., Singh, S., Mohd Ghazali, S., Cheong, Y. L., Md Iderus, N. H., Sundram, B. M., Aris, T. B., Mohd Ibrahim, H., Hong, B. H., \& Labadin, J. (2020). Modelling the effectiveness of epidemic control measures in preventing the transmission of COVID-19 in Malaysia. International Journal of Environmental Research and Public Health, 17(15), 5509 .

Lim, J. T., Maung, K., Tan, S. T., Ong, S. E., Lim, J. M., Koo, J. R., Sun, H., Park, M., Tan, K. W., Yoong, J., Cook, A. R., \& Dickens, B. S. L. (2021). Estimating direct and spill-over impacts of political elections on COVID-19 transmission using synthetic control methods. PLOS Computational Biology, 17(5), e1008959. https://doi.org/10.1371/journal.pcbi.1008959

Ling, S. (2021a, Feb 25). New Covid-19 cluster in Sarawak linked to CNY visits. The Star. https://www.thestar.com.my/news/nation/2021/02/25/new-covid-19-cluster-in-sarawaklinked-to-cny-visits

Ling, S. (2021b, May 11). Sarawak keeps to CMCO but with stricter SOP until May 17, says state committee. The Star. https://www.thestar.com.my/news/nation/2021/05/11/ sarawak-keeps-to-cmco-but-with-stricter-sop-until-may-17-says-state-committee

McCloskey, B., Zumla, A., Ippolito, G., Blumberg, L., Arbon, P., Cicero, A., Endericks, T., Lim, P. L., \& Borodina, M. (2020). Mass gathering events and reducing further global spread of COVID-19: a political and public health dilemma. The Lancet, 395(10230), 10961099. https://doi.org/10.1016/S0140-6736(20)30681-4

Metcalf, P. (1982). Borneo Journey into Death: Berawan Eschatology From Its Rituals. Philadelphia: University of Pennsylvania Press. 
Tawie, S. (2021, May 31). Sarawak DCM: Funeral gatherings responsible for 12 Covid-19 clusters, 3,725 positive cases and 31 deaths in state. Malaymail. https://www.malaymail.com/news/malaysia/2021/05/31/sarawak-dcm-funeralgatherings-responsible-for-12-covid-19-clusters-3725-po/1978369

The Star. (2021, May 26). Health DG: 12 community clusters linked to Raya celebrations found. The Star. https://www.thestar.com.my/news/nation/2021/05/26/health-dg-12community-clusters-linked-to-raya-celebrations-found 